\title{
Application of atmospheric correction in the measurement of land displacements using the PSInSAR technique, on the example of the Tahmoor mining region, Australia
}

\author{
Anna Kopeć1,* \\ ${ }^{1}$ Wroclaw University of Science and Technology, Faculty of Geoengineering, Mining and Geology, 27 Wyb. Wyspiańskiego St., \\ 50-370 Wroclaw, Poland
}

\begin{abstract}
InSAR (Interferometric Synthetic Aperture Radar) techniques are a very good tool for identification and observation of surface area displacements. Achieved accuracy of several centimeters, still do not allow for the quantitative analysis of the observed movements. Due to the high dynamics of phenomena in the Earth's atmosphere, one of the biggest limitations of InSAR are disturbances caused by changes in the atmosphere, between two measurements, on the basis of which an interferogram is created. In order to reduce the impact of the atmosphere on the SAR signal course, an atmospheric correction is applied.This study presents the results of calculations using the PSInSAR technique for the Tahmoor mining area located in south-eastern Australia, from 2006-2010. The atmospheric correction was determined: in an empirical way - on the basis of a linear relation between the signal phase and the topography of the area, based on data from the ERA - Interim weather model and data from the MERIS spectrometer.
\end{abstract}

\section{Introduction}

The underground mining exploitation has a significant impact on the surface area, which can cause, among others, the formation of low-maintenance pits. The range and size of vertical displacements of the area depends on many factors: geological and tectonic conditions, methods and operation time, as well as the geometrical location of the deposit. The shifting of the earth's surface can cause damage to buildings and technical infrastructure [1, 2]. Classic geodetic measurement techniques are characterized by very high accuracy, however, the result obtained is discrete and the measurement is time-consuming. The InSAR techniques are a modern and innovative tool for identifying and observing pseudo-vertical displacements of the terrain surface. Their advantage is a quasi-continuous representation, both in time and space. Achieved accuracy of several centimeters, still do not allow for the quantitative analysis of the observed movements. One of the biggest limitations of InSAR are disturbances caused by changes in the atmosphere, between two measurements, on the basis of which an interferogram is created $[1,3]$. In order to reduce the impact of the atmosphere on the SAR signal course, an atmospheric correction is applied. It is important that the determined atmospheric refraction values were best suited to the SAR data, both spatially and temporally. The atmospheric correction can be determined by several methods: empiric $[4,5]$, using weather models $[1,4]$, spectrometric data [6] and GNSS measurements [7].

\section{Basic theory}

The interferometric phase can be described as the sum of the following components $[8,9]$ :

$$
\phi=W\left\{\phi_{\text {ref }}+\phi_{\text {topo }}+\phi_{\text {defo }}+\phi_{\text {orb }}+\phi_{\text {atmo }}+\phi_{\text {scat }}+\phi_{\text {noise }}\right\}
$$

where:

$\phi$ - interferometric phase (phase difference between two images),

$W\{\bullet\}$ - the operator of the wrapped phase,

$\phi_{\text {ref }}$ - the component of the reference system in which heights are determined,

$\phi_{\text {topo }}$ - phase shift associated with terrain,

$\phi_{\text {defo }}$ - phase shift associated with land displacement,

$\phi_{\text {orb }}$ - phase shift associated with the inaccuracy of determining the orbit,

$\phi_{\text {atm }}$ - atmospheric delay,

$\phi_{\text {scat }}$ - phase shift resulting from the scattering properties of a given pixel,

$\phi_{\text {noise }}$ - phase noise.

An additional limitation are the temporal, spatial and geometrical decorrelations that reduce the coherence of signals. The first two result from the variable scattering characteristics, which may be caused by the change in the vegetative cycle phase between successive image acquisitions or the occurrence of the snow cover. The lack of a geometric correlation is dependent on the length of the orbital base, which affects the differences in the angle of incidence of the radar beam [8]. The decorrelations can be effectively eliminated using computational techniques

\footnotetext{
* Corresponding author: anna.kopec@pwr.edu.pl
} 
based on the processing of many images made at different times, for example the PSInSAR (Permament Scatter InSAR) technique described below [10] or the SBAS (Small Baseline Subset) technique [11].

\subsection{PSInSAR technique}

The PSInSAR technique was developed by Ferretti et al. [10]. It is based on the creation of differential interferograms between the master image and other images (slaves), and then taking into account only those pixels for which the reflection's intensity is strong and stable over time, and independent of the angle of incidence [9]. These pixels are called stable diffusers (PS), the decisive factor for qualifying a pixel as a PS is the level of decorrelation. The accuracy of the PSInSAR method depends on many factors: the SAR sensor used, the number of images, the time differences between individual acquisitions, the distance from the reference point and the mutual coherence of the diffusers [12].
In the case of measurements with InSAR techniques, the difference in atmospheric delay between the two acquisition of imaging is significant [13, 14]. Atmospheric delay, depending on the layer in which it occurs we can divide into: ionospheric and tropospheric. The ionospheric delay is only relevant for longer waves, in the $\mathrm{P}$ and $\mathrm{L}$ range, which are rarely used for InSAR measurements [14]. Most often, the atmospheric delay is considered as the impact of the troposphere on the SAR signal between the surface area and the upper limit of the troposphere (2):

$$
\phi_{\text {tropo }}=\frac{-4 \pi}{\lambda} \frac{10^{-6}}{\cos \theta} \int_{h}^{h_{\text {top }}}\left(N_{\text {hydr }}+N_{\text {wet }}\right) d x
$$

where:

$\theta$ - determines the angle of the wave,

$\lambda$ - wavelength,

$\frac{-4 \pi}{\lambda}$ - the ratio of transformation of pseudorange growth to phase delay.
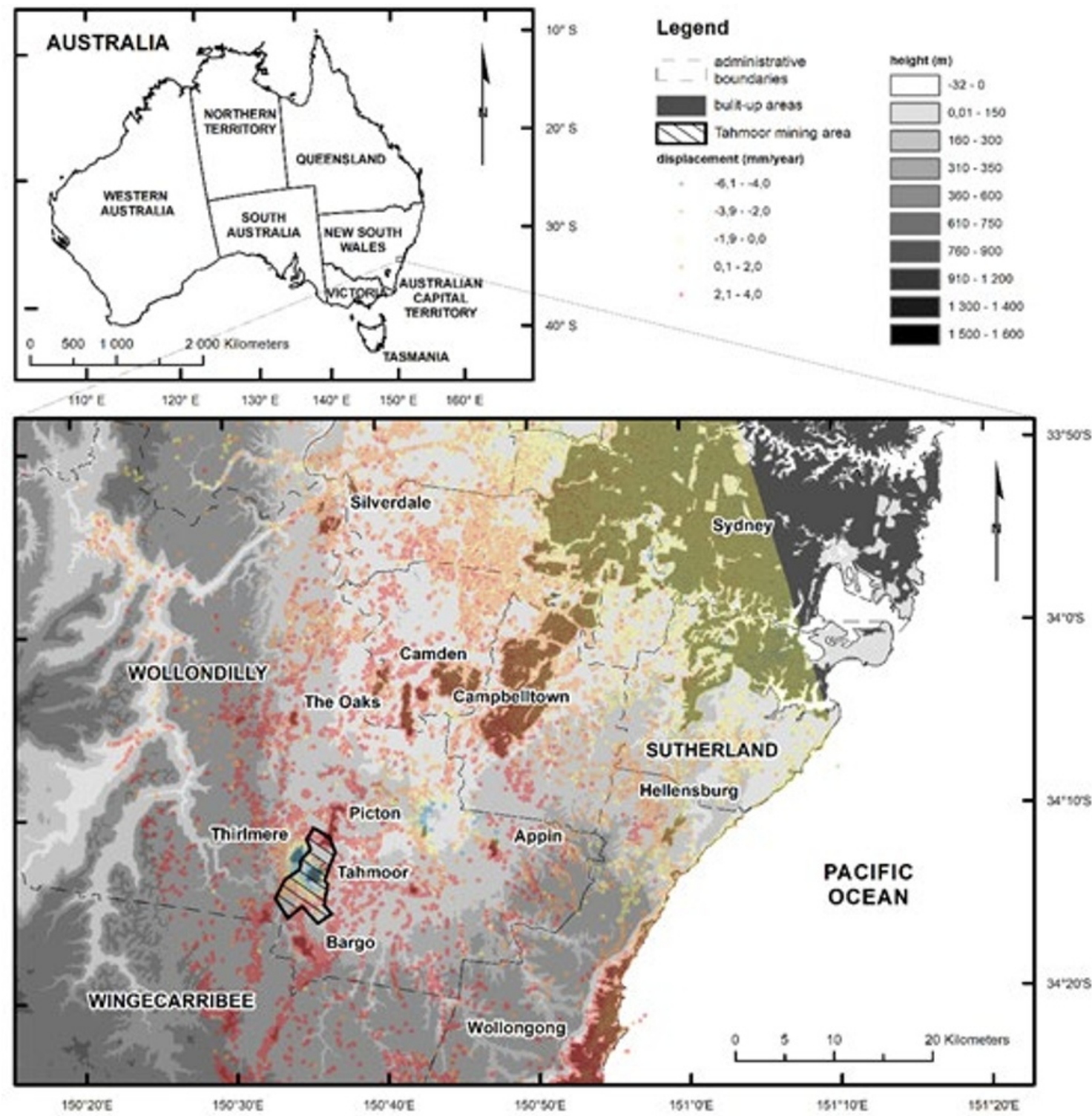

Fig. 1. Location of the research area of the Tahmoor mine. With cumulative mean displacement values. 


\subsection{The influence of the atmosphere}

With reference to the wet and dry constituent, tropospheric delay can be divided into two components resulting from the vertical, layered temperature distribution and dry air pressure as well as turbulent disturbances, which are the carriers of water vapour. The first one is relatively easy to model and usually correlates with the topography of the site. The second one due to the heterogeneous character is very difficult to determine [8], and its value is definitely more important in determining the correction for measurements using InSAR techniques.

\section{Area of research and displacements characteristics}

This article focuses on the mining area of Tahmoor, located on the south-east coast of Australia (New South Wales; Fig. 1). Coal mining was started in 1979, initially the operation was carried out with a room and pillar system. Since 1987, the operation has been carried out with a continuous longwall system, at a depth of 200 to $400 \mathrm{~m}$. In 2006-2010, the operation was carried out on longwalls from $23 \mathrm{~A}$ to 25 , extraction dates for walls relevant for these measurements are given in Tab. 1 [15].
Table 1. Start and end dates of exploitation on longwalls $22-25$.

\begin{tabular}{|c|c|c|}
\hline Longwall & Starting date & End date \\
\hline 22 & 31 May 2004 & 27 July 2005 \\
\hline $23 \mathrm{~A}$ & 13 September 2005 & 21 February 2006 \\
\hline $23 \mathrm{~B}$ & 22 March 2006 & 26 August 2006 \\
\hline $24 \mathrm{~A}$ & 14 October 2006 & 02 October 2007 \\
\hline $24 \mathrm{~B}$ & 15 November 2007 & 19 July 2008 \\
\hline 25 & 22 August 2008 & 21 February 2011 \\
\hline
\end{tabular}

The area of exploitation (Fig. 2) runs under the builtup areas (Tahmoor city), and such infrastructure facilities as railway lines (embankments and tracks), tunnels and culverts are the most endangered [16].

In the area of walls $24 \mathrm{~A}$ and 25 , twice higher settlement values were observed, compared to the forecasted values (Tab. 2). This is probably due to the flow of groundwater towards the Bargo River [15].

Table 2. Forecast and actual settlement values for longwalls 24 and 25.

\begin{tabular}{|c|c|c|}
\hline Longwall & $\begin{array}{c}\text { Forecasted } \\
\text { subsidence } \\
{[\mathbf{m m}]}\end{array}$ & $\begin{array}{c}\text { Real } \\
\text { subsidence } \\
{[\mathbf{m m}]}\end{array}$ \\
\hline $24 \mathrm{~A}$ & 509 & 1169 \\
\hline 25 & 768 & 1234 \\
\hline
\end{tabular}

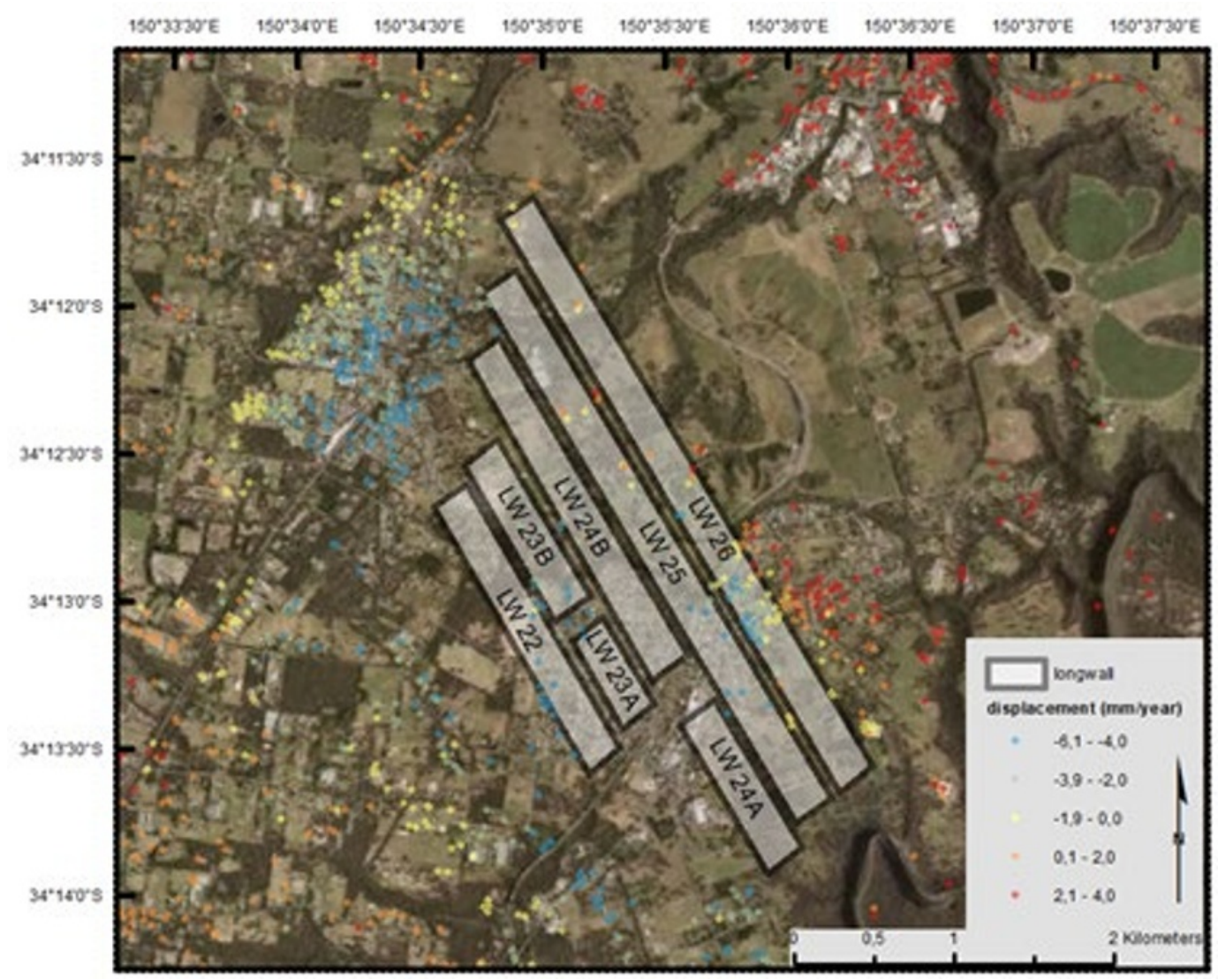

Fig. 2. The area of the Tahmoor mine with marked location of the walls exploited in 2004-2011. 


\section{Measurement data}

The actual measurements of displacements were carried out using the PSInSAR technique. 39 SAR images from the Envisat satellite (ASAR), made from June 2006 to September 2010, were used to perform the calculations (Tab. 3). As the reference image (master), the imaging was identified on May 2, 2008 (Fig. 3). Temporarily, the data includes operation on walls from 23B to 25 . However, the effect of field excavation may be visible even many months after its completion.

To determine the atmospheric correction by the linear method, only the interferograms were used directly. The amendment was determined on the basis of a linear relationship between the phase and the topography of the area, based on formula (3):

$$
\Delta \phi_{\text {tropo }}=K_{\Delta \phi} h+\Delta \phi_{0}
$$

where:

$K \Delta \varphi$ - the estimated relationship phase - topography, $h$ - ground level,

$\Delta \varphi_{0}$ - constant deviation coefficient relative to the entire inferferogram.

Determining of the delay is not differentiated into wetand dry refraction component, this is the total relative delay between master and the slave image [5]. In this method, the topography of the area is the most important. If the area on which the measurement is carried out is not varied (terrain denominations are small), this technique will not be effective $[12,17,18]$.

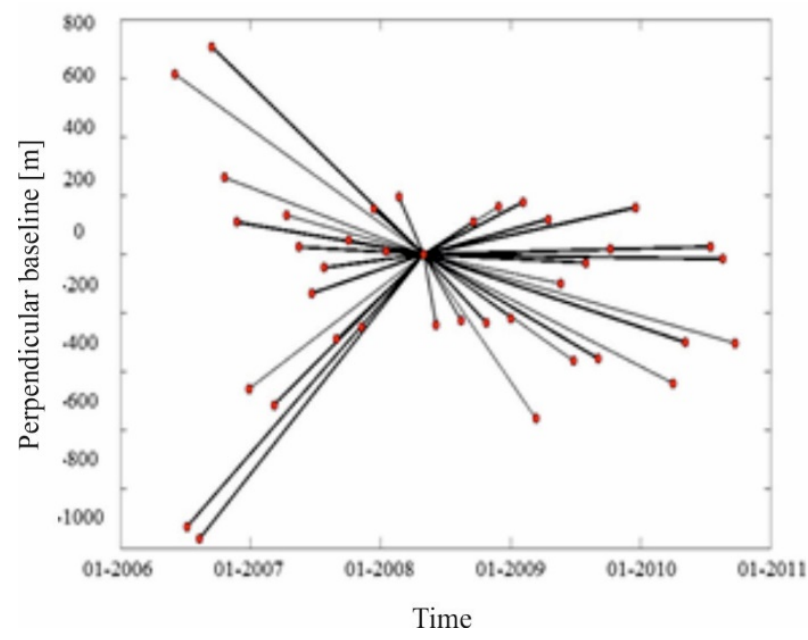

Fig. 3. Spatial and temporal bases of interferograms.

The atmospheric correction was also determined on the basis of data from the ERA-Interim weather model, the spatial resolution of which is about $80 \mathrm{~km}$ and the temporal distance is 6 hours. The model provides information on pressure and dry air temperature as well as air humidity [19].

In addition, a wet component of the atmospheric correction was determined based on spectrometric measurements. The calculations came from the MERIS spectrometer, which operated on the Envisat platform. For this reason, the data do not require time-space interpolation. The spectrometer is a passive device, therefore it can perform measurements only during the day and with relatively low cloud cover, therefore, the data are available not for every interferogram (Tab. 3). The spectrometric measurement consists in the acquisition of radiation on channels sensitive and insensitive to water vapour, which allows to determine the water vapour content in the atmosphere column (PWV). The results obtained from the MERIS spectrometer are supplemented by a dry delay component, based on data from the ERA-I weather model.

Table 3. Forecast and actual settlement values for longwalls 24 and 25 .

\begin{tabular}{|c|c|c|}
\hline Date & $\begin{array}{c}\text { Spatialbase } \\
{[\mathrm{m}]}\end{array}$ & $\begin{array}{c}\text { MERIS } \\
\text { data coverage } \\
{[\%]} \\
\end{array}$ \\
\hline 07July 2006 & 614.2 & 94.1 \\
\hline 11 August 2006 & -927.9 & 99.7 \\
\hline 15 September 2006 & -969 & 96.5 \\
\hline 20 October 2006 & 706.4 & 0.0 \\
\hline 24 November 2006 & 261.2 & 100.0 \\
\hline 29 December 2006 & 109.7 & 6.2 \\
\hline 09 March 2007 & -457.6 & 81.7 \\
\hline 13 April 2007 & -512.4 & 52.0 \\
\hline 18 May 2007 & 132.6 & 92.4 \\
\hline 22 June 2007 & 24.9 & 97.0 \\
\hline 27 July 2007 & -133.3 & 96.3 \\
\hline 31 August 2007 & -45.6 & 42.7 \\
\hline 05 October 2007 & -287.5 & 87.4 \\
\hline 09 November 2007 & 46.1 & 17.2 \\
\hline 14 December 2007 & -246 & 88.0 \\
\hline 18 January 2008 & 154.6 & 0 \\
\hline 22 February 2008 & 12.6 & 99.9 \\
\hline $\begin{array}{c}02 \text { May } 2008 \\
\text { (master) }\end{array}$ & 195.3 & 95.3 \\
\hline 06 June 2008 & -239.4 & 94.4 \\
\hline 15 August 2008 & -226.1 & 96.3 \\
\hline 19 September 2008 & 110.2 & 98.1 \\
\hline 24 October 2008 & -232.6 & 98.3 \\
\hline 28 November 2008 & 162.1 & 20.8 \\
\hline 02 January 2009 & -217.1 & 0 \\
\hline 06 February 2009 & 178.3 & 98.8 \\
\hline 13 March 2009 & -559.5 & 7.9 \\
\hline 17 April 2009 & 119.7 & 92.2 \\
\hline 22 May 2009 & -99.9 & 6.9 \\
\hline 26 June 2009 & -362.2 & 0.6 \\
\hline 31 July 2009 & -29.4 & 95.7 \\
\hline 04 September 2009 & -355.1 & 96.6 \\
\hline 09 October 2009 & 17 & 0.9 \\
\hline 18 December 2009 & 159.2 & 99.9 \\
\hline 02 April 2010 & -438.8 & 54.9 \\
\hline 07 May 2010 & -299.7 & 94.4 \\
\hline 16 July 2010 & 25.6 & 95.6 \\
\hline 20 August 2010 & -16 & 95.4 \\
\hline 24 September 2010 & -302.8 & 23.1 \\
\hline
\end{tabular}




\section{Results}

The results obtained with the PSInSAR measurement technique illustrate very well the location of the depression basin created as a result of exploitation in the area of the $24 \mathrm{~A}$ and 25 exploitation walls. The displacement values in Figures 1 and 2 are the cumulative values for the entire measurement period. The average annual subsidence over a period of approximately 4 years (2006-2010) reaches the value of approx. $20 \mathrm{~mm}$. However, more important are the values observedat the moment of direct impactof the active exploitation longwall on the surface, which range from 60 to 100 $\mathrm{mm} /$ year. These values are comparable to the levelling measurements performed by the mine (Tab. 2). In the years 2006-2007, the displacements reached the highest values, which was the result of the 24A longwall exploitation.

The graphs (Fig. 4) present the results for individual interferograms, taking into account the corrections applied for the A-A' cross-section (Fig. 5). It should be noted that the lack of continuity of the cross-section results from the point-based representation of the results in the form of PS points. The land displacements are visible on the cross-section in the range from $26,500 \mathrm{~m}$ every $34,000 \mathrm{~m}$ (on a stretch of $7.5 \mathrm{~km}$ length). In this case, subsidence is continuous, therefore for the imaging done before the master display (2 May 2008), the values (in radians) will be lower in comparison to the area that is not decreasing. For images taken after master imaging, they will reach higher values. This is due to the reference of results to one master display. It should also be noted that after transforming the values into metric units, their sign changes. This is due to formula (4):

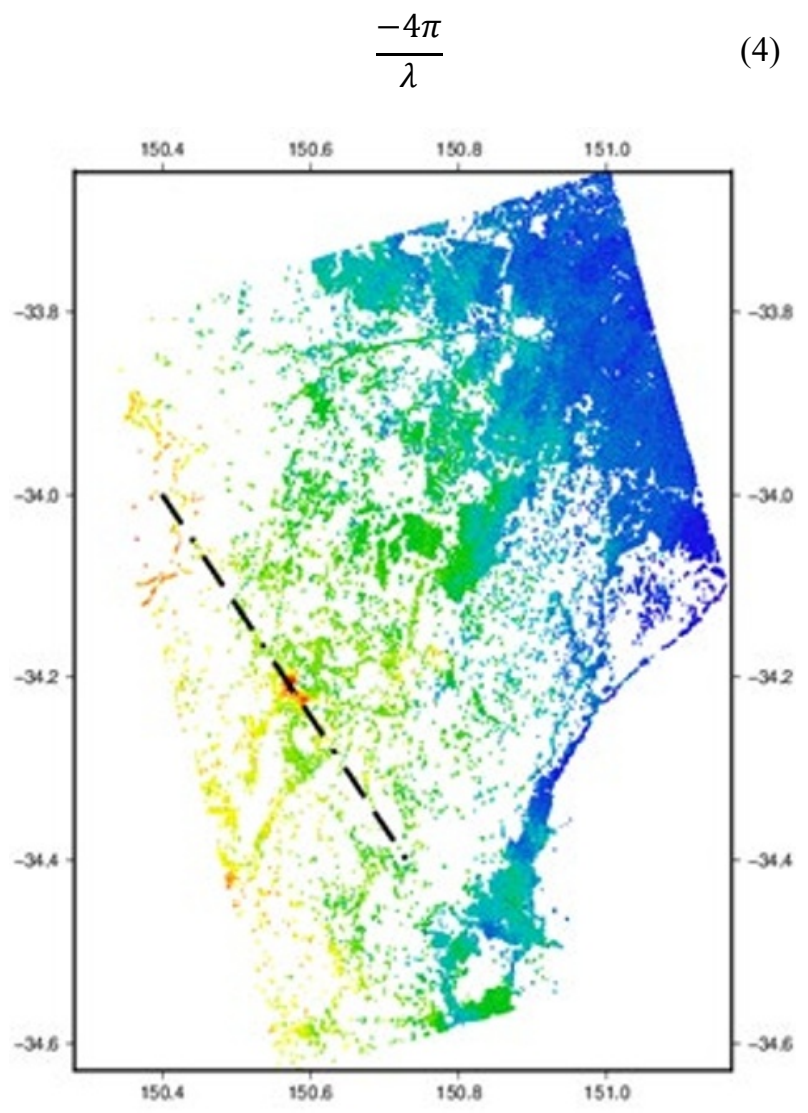

Fig. 5. The location of the cross- section through the investigated area.

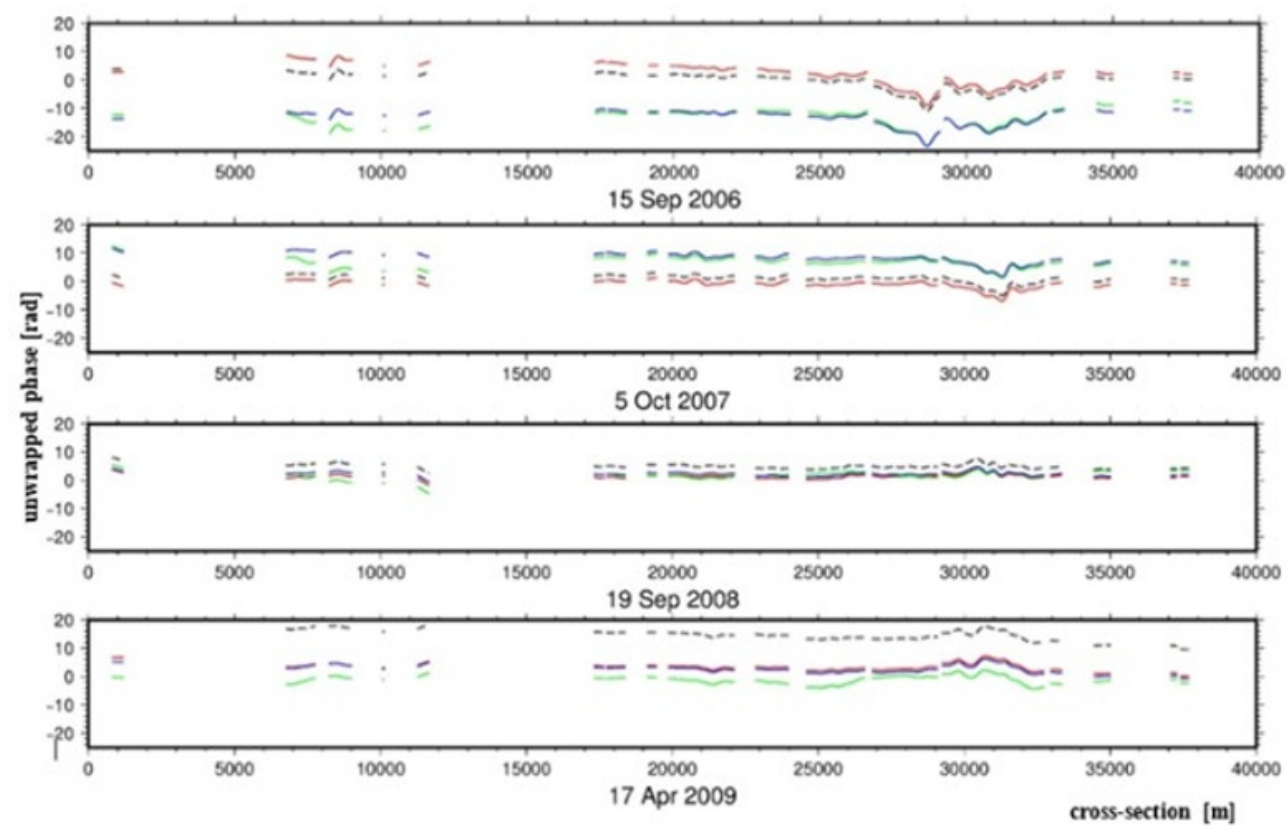

Fig. 4. Section A-A' for four interferograms (selected dates). The unwrapped phase reduced by DEM and orbits errors is marked with a dashed line, a red line additionally amended atmospheric correction determined by an empirical method (linear), a blue line amended with correction determined on the basis of data from the ERA-I weather model, a green line amended correction designated on the basis of MERIS spectrometric data (wet component) and data from the ERA-I weather model (dry component). The results are presented in radians. 
Analyzing the results for the unwrapped phase, reduced by DEM and orbit errors and taking into account the atmospheric correction - determined by different methods (Fig.6), it should be noted that it achieves the value of even a dozen or so radians (15 August 2006 and 17 April 2009), which indicates significant influence of the atmosphere. The smallest (absolute) correction values were observed using the empirical (linear) correction method. In addition, the results for this method significantly deviate from the values determined by means of spectrometric data and the weather model. This is due to small height difference, up to a maximum of several hundred meters. On the cross-section, there is a large correlation between the correction value, determined on the basis of spectrometric data and the
ERA-I weather model. The results, based on spectrometric measurements, were supplemented with a dry component from the weather model, however its value is low compared to the wet component of the delay (Fig. $6)$.

The largest delay values are visible for the wet component determined on the basis of spectrometric data (Fig. 6). Their distribution is heterogeneous and very dynamic.

It can be seen that the highest (absolute) values occur in the coastal region and in the highly urbanized area of Sydney. In the area of the Tahmoor mine, there are not observed any specific disturbances, the impact of moist air masses from the ocean is no longer reflected in a visible way in the atmospheric correction. a)

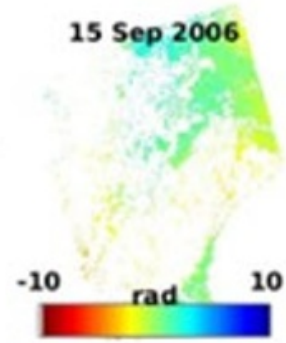

b)

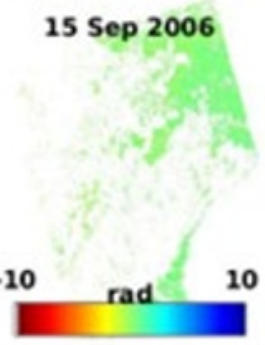

$15 \operatorname{Sep} 2006$

c)

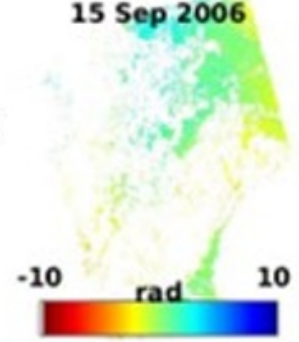

d)

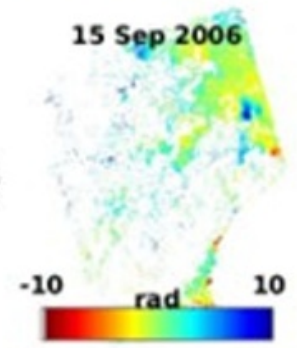

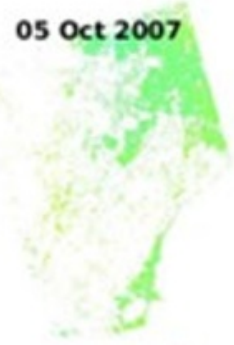

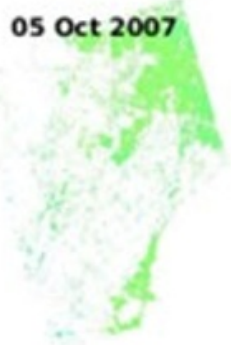

05 Oct 2007
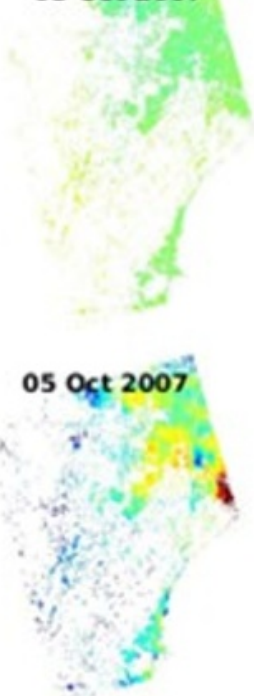
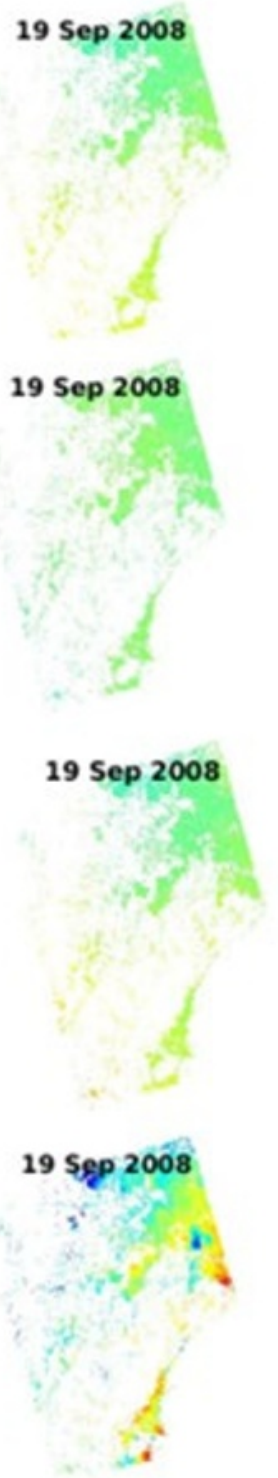

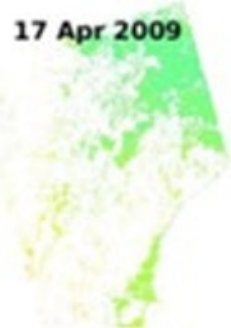

17 Apr 2009

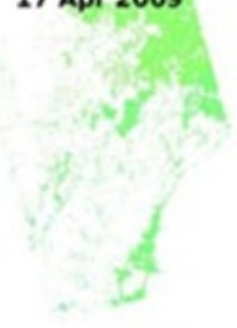

17 Apr 2009
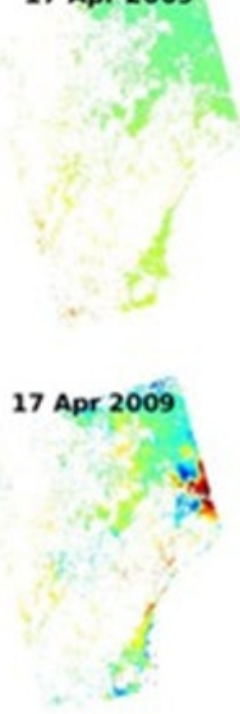

Fig. 6. Atmospheric delay for four selected interferograms (analogous to Fig.5), a) determined by empirical (linear) method, b) dry component determined based on weather data of the ERA-I model, c) wet component determined based on weather data of the ERA model -I, c) wet component determined on the basis of spectrometric data (MERIS). 


\section{Summary}

The impact of the Earth's atmosphere on measurements by InSAR techniques is very diverse and depends mainly on the phenomena occurring in the troposphere. The measurements made and their analysis confirmed the ineffectiveness of the empirical correction for relatively flat areas. In the area of the Tahmoor mine, very high delay values were not observed, however its values are significant for the measurements performed using the PSInSAR technique. The selection of an appropriate method for determining the atmospheric correction is very important. In the present case, due to the higher delays of the wet component, application of the correction determined on the basis of spectral data (wet component) and from the weather model (dry component) seems to be correct.

The results of measurements using InSAR techniques, due to the influence of various factors, allow mainly for the quantitative analysis of displacements. We should strive to increase the accuracy of the data, so that they can constitute qualitative information.

Partially processed SAR images were used in the paper in the form of single look complex (SLC) images form the European Space Agency. The DORIS software [10] and StaMPS software [11] were used for the PSInSAR calculations. The tropospheric correction was performed using the TRAIN software [1]. The data from the European Space Agency - the spectrometric MERIS data, and the data from the European Centre for Medium-Range Weather Forecasts (ECMWF) - the ERA-I weather model, were used to determine the tropospheric delay.

\section{References}

1. D.P.S. Bekaert, R.J. Walters, T.J. Wright, A.J. Hooper, D.J. Parker, Remote Sens. Environ., 170, 40 (2015)

2. F. Bell, T. Stacey, D. Genske, Environ. Geol., 40, 135 (2000)

3. M.-P. Doin, C. Lasserre, G. Peltzer, O. Cavalié, C. Doubre, J. Appl. Geophys., 69, 35 (2009)

4. Y.N. Lin, M. Simons, E.A. Hetland, P. Muse, C. DiCaprio, Geochem. Geophys. Geosyst., 11 (2010)

5. D.P.S. Bekaert, A. Hooper, T.J. Wright, J. Geophys. Res. B: Solid Earth, 120, 1357 (2015)

6. Z. Li, E.J. Fielding, P. Cross, R. Preusker, Int. J. Remote Sens., 30, 3343 (2009)

7. F. Onn, H.A. Zebker, J. Geophys. Res., 111, 2517 (2006)

8. R.F. Hannsen, Radar interferometry: Data interpretation and error analysis (Kluwer Acad. Publ., Dordrecht, 2001)

9. B. Kampes, R, Hanssen, Z. Perski, FRINGE (2003)

10. A. Ferretti, C. Prati, F. Rocca, IEEE Trans. Geosci. Remote. Sens., 39, 8 (2001)

11. P. Berardino, G. Fornaro, R. Lanari, E. Sansosti, IEEE Trans. Geosci. Remote. Sens., 40, 2375 (2002)

12. A. Hooper, D. Bekaert, K. Spaans, M. Arikan, Tectonophysics 514-517, 1-13 (2012)

13. D. Massonnet, K.L. Feigl, Rev. Geophys., 36, 441 (1998)

14. R. Goldstein, Geophys. Res. Lett., 22, 2517 (1995)

15. XSTRATA, Tahmoor Colliery Longwall25, End of Panel Subsidence Monitoring Report (2011)
16. XSTRATA, Tahmoor Colliery Longwalls 24 to 26, Surface safety and serviceability management plan (2006)

17. O. Cavalie, M-P. Doin, C. Lasserre, P. Briole, J. Geophys. Res., 112, 3403 (2007)

18. A. Kopeć, E3S Web Conf., 29, 22 (2018)

19. D.P. Dee, S.M. Uppala, A.J. Simmons, P. Berrisford, P. Polia, S. Kobayashi, U. Andrae, M.A. Balmaseda, G. Balsamo, P. Bauer, P. Bechtold, A.C.M. Beljaarsa, L. van de Berg, J. Bidlot, N. Bormann, C. Delsol, R. Dragani, M. Fuentes, A.J. Geer, L. Haimberger, S.B. Healy, H. Hersbach, E.V. Holm, L. Isaksen, P. Kallberg, M. Kohler, M. Matricardi, A.P. McNally, B.M. Monge-Sanz, J.-J. Morcrette, B.-K. Park, C. Peubey, P. de Rosnay, C. Tavolato, J.-N. Thepautand F. Vitart, Q. J. R. Meteorol. Soc., 137, 553 (2011) 